\title{
doispontos:
}

\section{Modernização ocidental e teoria política marxista: uma alternativa ao liberalismo}

\author{
Leno Francisco Danner \\ leno_danner@yahoo.com.br \\ Universidade Federal de Rondônia (UNIR), Porto Velho, RO, Brasil
}

\begin{abstract}
Resumo: partindo de uma crítica à noção de modernização como auto-diferenciação, autorreferencialidade e autossubsistência institucional sistêmica, assumida pelo liberalismo conservador e pela nova esquerda, argumento que tal modelo de teoria sistêmica referente à modernização leva tanto à autonomia e ao fechamento institucional sistêmico em relação a uma práxis política direta e a uma noção vinculante de normatividade social, quanto ao institucionalismo forte em economia política e em teoria política. A modernização, desde uma perspectiva institucional sistêmica, significa que cada sistema social tem uma lógica e uma dinâmica muito própria e particular, que é não-política e não-normativa, apenas técnica. Assim, instituições sistêmicas tornam-se despolitizadas, deslegitimando um modelo de práxis política democrática radical, que possa enquadrar os sistemas sociais a partir de uma participação democrática inclusiva, baseada em uma concepção vinculante de normatividade social. Como consequência, instituições sistêmicas centralizam e monopolizam a constituição, a legitimação e a evolução de seu próprio campo de reprodução social, fechando-o e autonomizando-o em relação à práxis política democrática e à normatividade social. Argumento que tal entendimento conservador da modernização ocidental pode ser substituído pelo entendimento marxista dessa mesma modernização ocidental, que está baseado na compreensão da sociedade como uma totalidade imbricada em suas partes, isto é, a interseção entre infraestrutura e superestrutura como o ponto de partida epistemológico-político para uma teoria social crítica e para uma práxis política democrática. Tal ponto de partida teórico-político marxista possibilita uma teoria social crítica e uma práxis política de esquerda fundadas na politização dos sistemas sociais como sua profunda ligação e enraizamento no mundo social e como dinâmica político-normativa.
\end{abstract}

Palavras-Chave: Modernização Ocidental; Teoria Sistêmica; Conservadorismo; Nova Esquerda; Política.

\section{Western modernization and marxist political theory: an alternative to liberalism}

\begin{abstract}
Western modernization as systemic institutional self-differentiation, self-referentiality and self-subsistence, I argue that such model of systemic theory regarding the modernization leads both to the systemic institutional autonomy and closure in relation to a direct political praxis and to a binding notion of social normativity, and to the strong institutionalism in political economy and in institutional political praxis. Modernization from a systemic institutional perspective means that each social system has very proper and particular logic and dynamic, which are non-political and non-normative, just technical. So, systemic institutions become depoliticized, delegitimizing a model of radical democratic political praxis which can frame social systems from an inclusive democratic participation based on a conception of social normativity. As consequence, systemic institutions centralize and monopolize the constitution, the legitimation and the evolution of their own field of social reproduction, closing and autonomizing it concerning the democratic political praxis and the social normativity. I argue that such conservative understanding of the Western modernization can be substituted by the marxist understanding of the Western modernization, which is based on the comprehension of the society as a totality imbricated in its parts, i.e. the intersection between infrastructure and superstructure as the epistemological-political starting point both to a critical social theory and to a democratic political praxis. Such marxist theoretical-political starting point enables a critical social theory and a leftist political praxis founded on the politicization of the social systems, as their profound linking and rooting in the social world and as a political-normative dynamic. Key-Words: Western Modernization; Systemic Theory; Conservatism; New Left; Marxism; Politics.
\end{abstract}




\section{CONSIDERAÇÕES INICIAIS}

Existe uma concepção hegemônica da modernização ocidental que é compartilhada por posições teóricopolíticas tão diferentes e tão contrapostas como o são o liberalismo conservador contemporâneo (Friedrich August von Hayek, Milton Friedman e Robert Nozick) e a atual nova esquerda (Jürgen Habermas e Anthony Giddens $)^{1}$. Ambas as posições teórico-políticas têm em comum não apenas a aberta contraposição ao socialismo real e, aqui, ao marxismo, mas também o mesmo entendimento da modernização ocidental - de fato, este é o sentido das afirmações de Habermas e de Giddens de que o liberalismo conservador tem razão no que diz respeito à sua crítica contra as excessivas centralização e totalização políticas do socialismo (cf. HABERMAS, 1997; GIDDENS, 1996). Ora, qualéeste similar entendimento da modernização ocidental que é compartilhado pelo liberalismo conservador e pela nova esquerda? É a noção de modernização ocidental como auto-diferenciação, autorreferencialidade e auto-subsistência institucional sistêmica. E o que ela significa? Ela significa que com a modernização ocidental - primeiro na Europa e depois no resto do mundo colonizado por tal forma de modernização - emergem e se consolidam sistemas sociais que, como instituições, centralizam e monopolizam campos específicos da reprodução social enquanto esferas sociais particulares, possuidoras de uma lógica e de uma dinâmica de funcionamento e de programação muito próprias, cuja estruturação e legitimação são preponderante e basicamente internas aos próprios sistemas sociais - o mercado capitalista e o Estado burocrático-administrativo moderno são os principais exemplos das especificidades da modernização ocidental, tanto para a nova esquerda quanto para o liberalismo conservador.

Argumentarei, neste artigo, que tal compreensão da modernização ocidental baseada na auto-diferenciação, na autorreferencialidade e na auto-subsistência sistêmica leva diretamente (no caso do liberalismo conservador) e mesmo indiretamente (no caso da nova esquerda) ao institucionalismo forte em relação à legitimação e à realização da evolução social. De fato, a compreensão institucional sistêmica afirma um duplo ponto de partida enquanto condição para a constituição institucional e para a evolução social, a saber: (a) cada sistema social centraliza e monopoliza a estruturação e a legitimação de seu campo social específico, tornando-se a própria esfera social que ele representa; e (b), por causa disso, cada campo social, desde uma compreensão institucional sistêmica, tem uma lógica de funcionamento e de programação muito própria, o que implica em um processo de constituição e de legitimação específico que não pode sofrer intervenção desde fora ou que não pode ser substituído por mecanismos e princípios alienígenas. Aqui surge o institucionalismo forte: cada instituição sistêmica centraliza e monopoliza seu campo social específico, tornando-se fechada, autorreferencial e auto-subsistente no que se refere a outros contextos, bem como adquirindo uma constituição e uma legitimação fortemente técnicas e lógicas; instituições sistêmicas autorreferenciais e auto-subsistentes negam sua constituição, sua dependência e uma legitimação normativo-políticas, no sentido de que elas não podem receber intervenção por parte de uma praxis política ou por uma noção vinculante de normatividade social (elas são fundamentalmente instituições e processos técnicos e lógicos, uma estrutura não-política e não-normativa).

Desse modo, uma práxis política democrática e inclusiva em relação aos sistemas sociais é deslegitimada por essa noção de auto-diferenciação, autorreferencialidade e auto-subsistência institucional sistêmica, já que tais instituições sistêmicas possuem uma constituição, uma legitimação e uma evolução técnicas e lógicas, que são não-políticas e não-normativas. Em outras palavras, conforme penso, a raiz de todos os problemas políticos e epistemológicos contemporâneos no que diz respeito à interpretação e à resolução da crise sócio-econômica global e à desestruturação do Estado de bem-estar social consiste nesta compreensão liberal conservadora, que é hegemônica hoje, marcada pelo entendimento da modernização 
ocidental como auto-diferenciação, autorreferencialidade e auto-subsistência institucional sistêmica, que despolitiza a constituição, a legitimação e a evolução dos sistemas sociais, enfraquecendo uma práxis política democrática e inclusiva, baseada em uma noção de normatividade social que tenha capacidade de enquadrar e de orientar a dinâmica institucional sistêmica a partir de valores de uso, e não apenas desde valores de troca. Ora, a teoria política marxista pode oferecer uma compreensão alternativa (e mais efetiva) de modernização ocidental contra essa posição liberal conservadora: de acordo com um ponto de partida epistemológico-político fundamental de Karl Marx, a sociedade deve ser entendida como uma totalidade que não pode ser separada em sistemas sociais autorreferenciais, auto-subsistentes, autônomos e fechados, baseados em uma constituição e em uma dinâmica técnica e lógica. A constituição, a legitimação e a evolução da sociedade dependem de uma reprodução social material que é fundamentalmente política: ela é realizada enquanto vida econômica por classes sociais em conflito, e não por instituições sistêmicas autonomizadas, imparciais e neutras - e aqui a economia não significa uma esfera técnica e lógica, mas sim um mundo propriamente político-normativo em permanente dinamicidade e conflito.

Portanto, a teoria política marxista, no momento em que concebe a sociedade como totalidade, no momento em que entende a constituição, a legitimação e a evolução societais enquanto uma práxis normativo-política dinamizada por lutas entre classes sociais, oferece uma base normativo-política muito profícua para o entendimento e para o enquadramento da crise da modernização ocidental contemporânea. Tal crise não é um problema técnico e lógico, da mesma forma como ela não pode ser compreendida e resolvida a partir de reformas técnicas e lógicas que recusam a constituição política e normativa da economia; ela deve ser politizada, ou seja, a constituição normativo-política da modernização deve ser afirmada como a base para uma práxis política democrática direcionada ao entendimento e à resolução de tal crise socioeconômica atual, algo que o marxismo faz. Acima de tudo, a teoria política marxista nos ensina que a compreensão da modernização ocidental enquanto auto-diferenciação, autorreferencialidade e auto-subsistência institucionais sistêmicas é a compreensão liberal da modernização ocidental, e não uma compreensão idealizada, essencialista ou naturalizada da modernização ocidental como um todo. Isso significa que a compreensão da modernização ocidental é uma compreensão política ligada a projetos políticos de hegemonia de classe. Este é, eu repito, o ponto de partida epistemológico-político para o entendimento da atual crise da modernização, bem como para a fundamentação de uma práxis política democrática e emancipatória que enfrente o crescimento do conservadorismo teórico-político.

\section{A COMPREENSÃO LIBERAL CONSERVADORA DA MODERNIZAÇÃO OCIDENTAL}

O liberalismo conservador de Friedrich August von Hayek é uma contraposição direta às posições teórico-políticas socialistas e social-democratas (que são a mesma coisa, de acordo com Hayek) em dois pontos específicos: contra a noção de normatividade social enquanto o critério basilar para a legitimação institucional; e contra o papel político interventor das instituições com o objetivo de conciliar capital e trabalho no contexto das instituições políticas (e por meio da ação política institucional) (cf.: HAYEK, 1987, p. 05-08; BUTLER, 1987, p. 27). As posições teórico-políticas social-democratas possuem, como sua plataforma, um modelo de política institucional baseada na centralidade das instituições políticas no que se refere à constituição e à evolução socioeconômicas ao longo do tempo. Aqui, há uma ligação e um enraizamento social da economia e da política, no sentido de que tanto a economia quanto as instituições políticas dependem da constituição normativa do mundo da vida, pelo menos em um sentido muito importante. Assim, a tentativa institucional de conciliar capital e trabalho por meio do Estado de bem-estar social é a principal característica da social-democracia, e ela significa praticamente uma intervenção política indireta no mercado, a ênfase nos direitos sociais e a intersecção entre as classes capitalista e trabalhadora em relação a acordos recíprocos concernentes a salários e regimes de trabalho. O ponto epistemológico-político 
fundamental da social-democracia consiste em seu reconhecimento de que a economia é um campo social estrutural que influencia e que determina a estratificação social e o acesso ao poder político, ao mesmo tempo em que ela está enraizada na reprodução normativa do mundo social, definindo fortemente essa mesma reprodução social normativa (cf.: BERNSTEIN, 1982; ABENDROTH, 1977; OFFE, 1984, 1994; BOBBIO, 1996; HOOK, 1999; KOLAKOWSKI, 1999; HARRINGTON, 1999; HABERMAS, 1991, 1997, 2009; ROSANVALLON, 1998; Sping-ANDERSEN, 2008; HARTMANN \& HONNETH, 2009).

Ora, a contraposição de Hayek ao socialismo e à social-democracia está fundada na noção de uma evolução espontânea da sociedade. Ela significa que a progressiva constituição da sociedade e a consolidação das instituições ou dos sistemas sociais não são resultado de uma intervenção política direta ou de um processo de engenharia sócio-política, mas sim a consequência de um processo inconsciente de evolução baseado no individualismo espontâneo. Esta ideia significa que a evolução social e institucional não é uma engenharia política fundada no planejamento político realizado pelas instituições e nem em uma práxis política consciente que escolhe deliberadamente o que alguém ( $a$ sociedade) quer, como alguém ( $a$ sociedade) quer e onde alguém ( $a$ sociedade) deseja ir. Não existe tal tipo de práxis política autoconsciente feita pela sociedade como um todo, como se a sociedade fosse um macro sujeito muito personalizado ou mesmo uma classe social superdimensionada com condições de decidir por todas as pessoas (e com todas as pessoas) a sua própria constituição e a sua própria evolução ao longo do tempo. Contrariamente a isso, diz Hayek, a evolução social é particularizada, ou seja, ela é feita por cada indivíduo singular que busca basicamente seu próprio interesse pessoal. Este indivíduo não tem uma visão estrutural ou uma autoconsciência messiânica da totalidade social da qual ele faz parte. Ele apenas deseja satisfazer seu desejo egoísta, pondo suas próprias habilidades para o uso de outros indivíduos, com vistas a alcançar aquele desejo egoísta. E este é o único padrão epistemológico-moral-político para a consideração da evolução social e da constituição institucional (cf. HAYEK, 1948, p. 01-32; 1987, p. 38-47).

A evolução social é uma soma de ações individualizadas e particularizadas que geram e que consolidam ao longo do tempo códigos, práticas e instituições, que definem a interação social e as reivindicações normativas. Acima de tudo, tal evolução não é resultante de uma práxis política coletiva e autoconsciente ou dinamizada por instituições políticas que regulam todos os sistemas sociais baseadas na ação política, ignorando a lógica e a dinâmica institucional sistêmica, que é sempre particularizada e individualizada, nunca totalizante ou definida a partir de ações em nível estrutural ou macro. A evolução social é fundamentalmente espontânea, no sentido de que cada indivíduo contribui com suas ações e com seus desejos particulares para a consolidação de códigos, de práticas e de instituições intersubjetivos que possibilitam exatamente esta mesma persecução individual do próprio interesse. Assim, regras, práticas e instituições intersubjetivas são como um contrato que regula ações e demandas individuais, da mesma forma como tais regras, práticas e instituições intersubjetivas impõem o modelo de um contrato entre indivíduos particulares enquanto o paradigma normativo-político para a constituição e para a legitimação institucionais. E indivíduos não são filósofos ou profetas com uma visão messiânica da totalidade, mas apenas seres particulares com uma visão de mundo própria e subjetiva - eles não agem em nome de toda a sociedade e de seus grupos, senão que somente em nome de seu próprio interesse particular, pessoal (cf. HAYEK, 1995, p. 49-59; BUTLER, 1987, p. 36).

A evolução social espontânea não é politicamente programável, da mesma forma como ela não pode sofrer intervenção ou mesmo ser conduzida por parte das instituições políticas e a partir de uma noção socialmente vinculante de normatividade baseada em uma ideia de sociedade enquanto totalidade, posto que tal ideia é uma fantasia: existem apenas indivíduos, não a sociedade, e cada indivíduo é responsável por seu próprio caminho e por suas próprias escolhas. De fato, o principal argumento de Hayek consiste 
em que não existe a sociedade enquanto uma totalidade autoconsciente que é imbricada em suas partes, mas apenas indivíduos. Aqui, a sociedade não é uma totalidade ou uma infraestrutura: uma infraestrutura é baseada no fato de que as instituições definem de maneira direta a estratificação social e a distribuição do poder; e uma infraestrutura, neste diapasão, é basicamente política, determinada pela hegemonia de classe e dinamizada pelas lutas sociais. Este é o ponto de partida epistemológico-político da esquerda (e particularmente do marxismo) em termos de formulação de uma teoria social crítica e de legitimação de uma práxis política democrática radical. Contudo, Hayek, no momento em que nega o sentido e os efeitos infraestruturais da sociedade, de suas instituições, recusa consequentemente o fato - fundamental para as teorias de esquerda - de que a sociedade tem uma organização e uma evolução institucionais que são definidas pela hegemonia política e pelas lutas sociais, da mesma forma como ele recusa que tal constituição institucional política determine tanto a estratificação social quanto o compartilhamento do poder. De acordo com Hayek, indivíduos particularizados são o único fato cientificamente verificável, cientificamente observável, e isto significa que a sociedade como uma infraestrutura ou como um super sujeito é pura e simplesmente uma construção idealizada da esquerda; da mesma forma, a centralidade tanto da práxis política quanto das instituições políticas não é possível em sociedades individualizadas que não possuem um núcleo básico a partir do qual elas fundam e influenciam todas as dinâmicas sociais (cf.: HAYEK, 1987, p. 86-97; BUTLER, 1987, p. 53; HARVEY, 2008, p. 31; HABERMAS, 2000, p. 82).

Desse modo, a política não é o centro da sociedade, além de não poder substituir a lógica e a dinâmica institucional sistêmica; também não pode substituir a ação individual no que diz respeito à evolução social e à consolidação do status quo. E a política não é o centro da sociedade pelo fato de que a sociedade não é uma totalidade ou uma infraestrutura homogênea, a sociedade ou as instituições políticas não podem ser responsabilizadas pelas desigualdades sociais e por qualquer forma de injustiça em absoluto. De fato, Hayek argumenta que o argumento básico da esquerda consiste em que a sociedade enquanto uma infraestrutura determina o status quo e as injustiças sociais, exatamente porque ela é uma infraestrutura dinamizada pelas lutas sociais entre classes sociais conflitantes, de modo que, nesta situação, é possível (e necessário) realizar-se reivindicações sociais normativas às instituições - e elas devem realizar tais reivindicações sociais normativas. Mas, para Hayek, esta é uma fantasia da esquerda baseada na idealização da sociedade como um super sujeito político ou como uma infraestrutura política. Em uma sociedade constituída basicamente por indivíduos, não existem instituições ou infraestruturas que definam e que determinem tanto a evolução social quanto o status quo; os indivíduos são a única infraestrutura, se se pode falar deste modo, ou seja, cada indivíduo é responsável por seu próprio caminho e por suas próprias escolhas, da mesma forma como ele é o único responsável pelas consequências do caminho e das escolhas que faz. Em uma sociedade constituída puramente por indivíduos, sem um núcleo ou uma infraestrutura comum, a meritocracia é o princípio epistemológico, normativo e político fundamental para a legitimação tanto do arranjo institucional quanto do status quo (cf. HAYEK, 2013, p. 302-309; BUTLER, 1987, p. 108; HERRNSTEIN, 1975, p. 147-174).

Uma consequência - certamente a maior consequência - da recusa, por Hayek, da noção de sociedade como uma infraestrutura é a correlata negação da ideia de normatividade social como uma base política para a constituição, a legitimação e a evolução institucionais. De fato, de acordo com o liberalismo conservador de Hayek, não há normatividade social e, portanto, o conceito de justiça social é uma miragem, uma fantasia da esquerda, se por ele se quiser significar a intervenção política sobre o status quo, sobre a dinâmica de mercado, o que implica na fundamentação normativa das instituições políticas - a justiça social está baseada no fato de que a sociedade é uma infraestrutura politicamente constituída e dinamizada que determina o status quo. A justiça social somente é possível como meritocracia, mas a meritocracia não impõe às instituições políticas reivindicações sociais normativas ou uma intervenção política na dinâmica de mercado, pelo fato de que essa mesma meritocracia nega a noção de sociedade como uma totalidade ou como uma 
infraestrutura política que define o status quo. Contrariamente a isso, a meritocracia origina e fundamenta uma política negativa, caracterizada pelo fato de que as instituições políticas perdem sua centralidade, da mesma forma como uma noção vinculante de normatividade social é deslegitimada como base política para o enquadramento da dinâmica de mercado e do status quo em geral. Em outras palavras, a meritocracia contrapõe-se à práxis política e à normatividade social, negando o planejamento e a condução políticos da evolução social como um todo (cf. HAYEK, 1987, p. 98-108; 1995, p. 73-94; 2013, p. 247-250, p. 273-275).

É importante considerar-se novamente a noção hayekiana de uma evolução social espontânea baseada no individualismo como a plataforma epistemológico-política da recusa liberal tanto da centralidade da práxis política quanto de uma noção vinculante de normatividade social. Como eu disse acima, tal ideia de uma evolução espontânea tem o objetivo de opor-se à concepção socialista e social-democrata de sociedade enquanto uma infraestrutura. Consequentemente, a noção de uma evolução espontânea nega a ênfase socialista e social-democrata na práxis política e na constituição normativa do social (incluindo, aqui, a esfera do mercado). Ora, aqui emerge a ideia hayekiana do mercado como uma ordem espontânea constituída e dinamizada por indivíduos particularizados. O mercado como uma ordem espontânea significa exatamente o fato de que as relações econômicas não são resultado de um planejamento político e nem que elas possam ser assumidas ou guiadas por parte das ações políticas institucionais e enquadrada por uma noção de normatividade socialmente vinculante. Ainda aqui o individualismo dá o mote para a evolução espontânea do mercado: cada indivíduo persegue seu próprio interesse como uma atividade econômica e na esfera econômica. Desse modo, nós podemos entender a evolução social como uma atividade e como uma evolução econômico-produtiva espontânea e não-programável, no sentido de que a sociedade, suas regras, seus códigos, suas práticas e suas instituições ganham existência, forma e sentido a partir dessa mesma esfera econômica realizada e dinamizada por indivíduos particularizados, que não têm uma autoconsciência messiânica ou total da sociedade enquanto uma infraestrutura - assim, práticas, normas e instituições sociais não são resultado de uma engenharia política, mas sim de uma ação econômica espontânea, feita por todos os indivíduos e por cada indivíduo em particular. $\mathrm{O}$ mercado enquanto uma ordem espontânea significa que os indivíduos particularizados, quando buscam seu próprio interesse como uma prática econômica, criam ao longo do tempo os melhores códigos, regras e práticas que garantem essa mesma espontaneidade econômica como a base da evolução social. Desse modo, aqui, não há legitimidade nem para a centralidade da política e nem para uma noção vinculante de normatividade social: a espontaneidade do mercado e o individualismo metodológico impõem a autorreferencialidade, a auto-subsistência e a autonomia da ordem econômica espontânea no que diz respeito à práxis política democrática e à normatividade social (cf.: HAYEK, 1995, p. 27-48, p. 95-122; 2013, p. 09-52).

Ora, o liberalismo conservador de Hayek assume a noção de modernização ocidental enquanto autorreferencialidade e auto-subsistência sistêmica como sua base epistemológico-política para a fundamentação das instituições sociais e políticas contemporâneas, enfrentando diretamente as posições socialistas e social-democratas, e atacando a constituição e a legitimação do Estado de bem-estar social, bem como os fundamentos normativos dos direitos sociais. Assim, tal entendimento liberal conservador da modernização ocidental concebe a emergência das sociedades modernas como uma evolução que é dependente do desenvolvimento espontâneo do mercado enquanto uma ordem autônoma e auto-subsistente. Tal ordem espontânea é não-política e não-normativa, basicamente imparcial e neutral no que se refere a reivindicações político-normativas, porque ela é baseada na espontaneidade econômica definida pela meritocracia. Aqui, não há nada político pelo fato de que não existe uma estrutura institucional politicamente dinamizada que defina o status quo; a meritocracia é o princípio fundamental que estabelece e que legitima esse mesmo status $q u o$, mas ela não é um princípio político ou normativo que requeira, que leve a uma política institucional interventora em relação ao mercado, baseada em normatividade social. A meritocracia somente exige o 
estrito respeito à espontaneidade do mercado, à autorreferencialidade e à auto-subsistência do mercado, o que significa a recusa da centralidade da práxis política.

\section{A COMPREENSÃO DE MODERNIZAÇÃO OCIDENTAL DA NOVA ESQUERDA}

A teoria da modernidade de Habermas é um exemplo da nova esquerda contemporânea que objetiva superar o marxismo enquanto base epistemológico-política para o entendimento da modernização ocidental, pelo menos em três pontos: (a) seu ponto de partida é - de modo similar ao liberalismo conservador (ainda que com conclusões diferentes) - a ideia de modernização como auto-diferenciação, autorreferencialidade e auto-subsistência sistêmica; (b) sua noção de sociedade complexa sem um núcleo ou centro a partir do qual a dinâmica social como um todo seria dinamizada; e (c) a recusa da noção de classes sociais ou de super sujeitos sociais com capacidade de agir politicamente em nome de toda a sociedade, assumindo uma concepção de normatividade social como seu mote em termos de práxis política (cf.: HABERMAS, 2012a, p. 09-12, p. 289, p. 387; 2012b, p. 278; 2003a, p. 17-18; 2003b, p. 105-106). Com efeito, o ponto de partida da teoria da modernidade de Habermas consiste na constatação sociológica de que a modernidade europeia emerge como um duplo e imbricado processo de evolução social, ou seja, como uma cultura normativa universalista baseada na secularização institucional e no individualismo (mundo da vida, nas palavras de Habermas) e como uma auto-diferenciação, autorreferencialidade e auto-subsistência institucional sistêmica (sistema, ainda nas palavras de Habermas) (cf. HABERMAS, 2012a, p. 140-141, p. 387-424; 2012b, p. 278-280). Este processo correlato leva à superação das sociedade tradicionais, particularmente em dois aspectos: primeiro, a naturalização, nas sociedades tradicionais, do status quo, no sentido de que todas as relações e práticas sociais das sociedades tradicionais são determinadas pelo mito e pela religião - não há secularização e nem uma noção de individualidade (no sentido moderno do termo, enquanto separada da cultura e da natureza), de modo que não há mobilidade social, criticismo social; segundo, a profunda imbricação entre política, economia e cultura das sociedades tradicionais, significando-se com isso que todos estes campos dependem de uma justificação normativa e global de sua dinâmica, da mesma forma como eles não podem ser concebidos independentemente da totalidade da qual eles fazem parte (cf. HABERMAS, 2012a, p. 94-112). Nesse sentido, a modernidade europeia é baseada na separação entre política, cultura e economia, as quais se tornam campos sociais particulares, cada um deles com lógicas e dinâmicas de funcionamento e de programação muito específicas (cf. HABERMAS, 2012a, p. 139; 1997, p. 143-144, p. 163).

A partir da daqui, ganha sentido a consolidação dos dois sistemas sociais modernos mais importantes e decisivos, a saber, o Estado burocrático-administrativo moderno e o mercado capitalista. Eles são instituições que monopolizam e que centralizam a constituição, a fundamentação e a evolução de campos sociais particulares, tornando-se os próprios campos sociais que monopolizam e centralizam. É importante e interessante considerar-se o fato de que a modernização ocidental, no momento em que ela é baseada em tal separação entre política, cultura e economia (auto-diferenciação sistêmica), assume a dinâmica institucional sistêmica como sua base de estruturação e de legitimação. De fato, a superação da noção de totalidade normativa das sociedades tradicionais e a consolidação da modernização ocidental como auto-diferenciação sistêmica têm como consequência tanto a profunda separação entre política, economia e cultura quanto a autorreferencialidade e a auto-subsistência sistêmica. Autorreferencialidade e autosubsistência significam que cada instituição moderna (no caso o mercado capitalista e o Estado) tem uma lógica de funcionamento e de programação muito própria, que é autônoma e capaz de desenvolver-se por si mesma apenas por meio de seus mecanismos internos, de modo que ela não necessita de contextos externos para sua evolução e para sua estabilização ao longo do tempo. Do mesmo modo, as instituições modernas, baseadas em e determinadas por tal processo de auto-diferenciação, autorreferencialidade e 
auto-subsistência institucional sistêmica, não possuem uma constituição e uma legitimação normativa, especialmente o mercado capitalista e o próprio Estado moderno, pelo menos em um sentido poderoso: cada um deles pode sempre afirmar sua autorreferencialidade, isto é, sua lógica de funcionamento e de programação interna e específica, só dele, como a única base para sua evolução, negando, por exemplo, a práxis política e a normatividade social.

Portanto, a auto-diferenciação, a autorreferencialidade e a auto-subsistência sistêmica da modernização ocidental institui dois pontos inultrapassáveis para a teoria política contemporânea, a saber: a diferenciação societal em instituições sistêmicas autônomas e fechadas, possuidoras de uma dinâmica de funcionamento e de programação basicamente interna, lógica e técnica; e a despolitização destas instituições sistêmicas, que se tornam fundamentalmente instâncias não-normativas, apenas instituições, dinâmicas e procedimentos técnicos e lógicos. Quaisquer compreensão e reformismo políticos devem partir do fato da auto-diferenciação, da autorreferencialidade e da auto-subsistência institucional sistêmica enquanto a base epistemológico-política da modernização ocidental; eles não podem interpretar instituições sociais sistêmicas desde uma noção político-normativa - eles devem respeitar o fato de que a mudança de cada sistema social é um procedimento interno que deve levar em conta sua dinâmica particular, lógica e técnica. Contrariamente às sociedades tradicionais, que seriam caracterizadas como uma totalidade normativa muito imbricada em suas partes, o que implicaria na centralidade da explicação e da ação normativas como o núcleo básico da dinâmica societal, a modernização ocidental é marcada por tal auto-diferenciação, autorreferencialidade e auto-subsistência institucional sistêmica, e isso significa tanto a recusa a reduzir a evolução social como um todo a um único fundamento político-normativo (ou mesmo a reduzi-la a uma questão político-normativa) quanto o fechamento e a autonomia institucional no que diz respeito à constituição e à legitimação político-normativa. A práxis política é altamente deslegitimada por meio da afirmação do fechamento e a da autorreferencialidade sistêmica, já que a constituição e a legitimação institucional sistêmica é basicamente técnica e lógica, interna a cada instituição sistêmica.

De acordo com Habermas, o que deve ser considerado é que as sociedades contemporâneas são sociedades complexas, ou seja, sociedades muito diferenciadas em vários campos particulares, centralizados e monopolizados por suas correspondentes instituições sistêmicas, com dinâmicas e com princípios de organização e de funcionamento próprios. Desse modo, sociedades complexas contemporâneas não representam uma totalidade que é fortemente imbricada em suas partes: cada campo social é dinamizado por uma instituição sistêmica específica (especialmente o Estado moderno e o mercado capitalista) que é altamente autorreferencial e auto-subsistente no que se refere ao contexto geral ao qual ela pertence. E, o que é muito importante, as sociedades complexas não são uma estrutura ou um super sujeito autoconsciente por causa dessa auto-diferenciação institucional sistêmica, o que significa que elas não possuem um núcleo basilar (qualquer que seja ele) a partir do qual a sociedade como um todo podesse ser interligada e transformada por qualquer tipo de ação institucional (e por meio da práxis política em particular), da mesma forma como tais sociedades complexas contemporâneas não podem realizar uma ação macro que subsuma todos os sistemas sociais particularizados, fechados e autorreferenciais, substituindo lógicas e dinâmicas institucionais sistêmicas por princípios político-normativos. No mesmo sentido, uma sociedade complexa, no momento em que ela é caracterizada pela existência de sistemas sociais diferentes, autônomos e fechados, não possui um centro a partir do qual uma dinâmica geral e uma ação institucional ou política direta possa enquadrar todos os sistemas sociais em conjunto. As sociedades complexas representam fundamentalmente a versão contemporânea e a consolidação definitiva do processo de modernização ocidental baseado na auto-diferenciação, na autorreferencialidade e na auto-subsistência sistêmica, e este é o ponto de partida epistemológico-político a partir do qual a teoria e a práxis política devem partir. Em outras palavras, a lógica e a dinâmica institucionais sistêmicas não podem ser ignoradas ou deixadas de 
lado por uma práxis política democrática radical que objetiva uma ação social e uma transformação política emancipatórias destas mesmas sociedades complexas contemporâneas, que são, como venho dizendo, fundadas na auto-diferenciação, na autorreferencialidade e na auto-subsistência sistêmica (cf. HABERMAS, 2003a, p. 17-20; 2003b, p. 23-25, p. 104-106).

Aqui emerge o sentido do paradigma jurídico-político procedimental de Habermas enquanto contraposição ao liberalismo conservador (paradigma jurídico-político liberal) e ao socialismo (paradigma jurídico-político republicano). De acordo com Habermas, o liberalismo conservador está errado em afirmar a radical individualização da sociedade, negando a existência sociológico-política de sistemas sociais possuidores de uma estrutura objetiva que pode influenciar e determinar o status quo e a distribuição do poder. Sistemas sociais são infraestruturas que realizam uma ação social macro, dinamizando a evolução social e a constituição institucional. Desse modo, a política negativa do liberalismo não é suficiente para resolver todos os problemas sociopolíticos concernentes à pobreza, ao status quo e à efetividade dos direitos individuais, da mesma forma como o laissez-faire e a meritocracia não garantem a estabilidade econômica e a justiça social. Instituições políticas e direitos sociais são necessários em termos de orientação da dinâmica econômica e da evolução social - e isso significa a centralidade do Estado de bem-estar social (cf.: 2003a, p. 335-337; 1998, p. 18-19). O republicanismo está equivocado pelo fato de não reconhecer a auto-diferenciação, a autorreferencialidade e a auto-subsistência institucional sistêmica enquanto a característica básica da modernização ocidental contemporânea. Ao não reconhecer tal especificidade da modernização ocidental, o republicanismo intenciona uma intervenção política direta em todos os sistemas sociais e particularmente na dinâmica de mercado, substituindo as lógicas e as dinâmicas internas dos sistemas sociais por princípios político-normativos. Com efeito, o republicanismo, ainda segundo Habermas, põe a práxis política direta enquanto a base da evolução social como um todo, ignorando exatamente a complexidade social contemporânea, ou seja, o fato de que as nossas atuais sociedades são fundadas em e dinamizadas por tal auto-diferenciação, autorreferencialidade e auto-subsistência sistêmica, o que significa que cada sistema social tem uma lógica e uma dinâmica de programação e de funcionamento muito próprias a cada um deles, ao mesmo tempo em que a política já não é mais o centro da sociedade. E a sociedade já não é mais uma totalidade muito imbricada em suas partes, significando isso que não há um núcleo e uma instituição central a partir da qual a evolução social é dinamizada e realizada (cf. HABERMAS, 2003a, p. 331-332). Ora, se uma práxis política radical significa tanto uma intervenção político-normativa direta na lógica autônoma e fechada dos sistemas sociais quanto a centralidade das instituições políticas no que diz respeito à efetivação da evolução social, então tal tipo de política radical já não é mais possível hoje em sociedades complexas baseadas no processo de modernização ocidental como auto-diferenciação, autorreferencialidade e auto-subsistência sistêmica.

Além disso, Habermas diz que o republicanismo está errado ao conceber a sociedade como totalidade e os sujeitos políticos como classes sociais, isto é, como super sujeitos sociais, como macro sujeitos sociais. De fato, neste último caso, o republicanismo está enraizado em uma ideia antiquada da divisão social e da constituição política em classes sociais conflitivas, como o marxismo faz (cf. HABERMAS, 2003b, p. 21). Assim, desde este ponto de partida epistemológico-político, o republicanismo enfatiza tanto uma práxis política direta em todos os sistemas sociais (particularmente o mercado e o Estado), substituindo suas lógicas e dinâmicas de funcionamento e de programação específicas e internas por princípios político-normativos (como eu disse acima), quanto principalmente a monopolização da normatividade social por classes sociais emancipatórias, ao estilo do proletariado. Ora, esta última noção republicana é muito importante para entender-se não apenas o próprio republicanismo, mas também uma nova característica das sociedades complexas contemporâneas baseadas no processo de institucionalismo sistêmico da modernização ocidental. De acordo com o marxismo (que é uma forma de republicanismo), como a dinâmica social e a constituição 
institucional são determinadas pela hegemonia de classe, devemos ligar normatividade social $e$ classes sociais emancipatórias. Esta mesma normatividade social não pode ser centralizada ou monopolizada pelas próprias instituições, pelo fato de que as instituições não são neutras e imparciais, mas sim um resultado da hegemonia de classe. Em outras palavras, a normatividade social não é a mantida, fundada e dinamizada por instituições jurídico-políticas, mas fundamentalmente por classes socais emancipatórias, cuja hegemonia político-normativa é feita por meio de, a partir de lutas sociais.

É neste ponto que o paradigma jurídico-político procedimentalista de Habermas ganha forma. Por um lado, ele nega a radical individualização da sociedade levada a efeito pelo liberalismo conservador, afirmando que a modernização ocidental é caracterizada como um processo de auto-diferenciação, autorreferencialidade e auto-subsistência sistêmica, o que significa o fato de que os sistemas sociais são estruturas objetivas que determinam o status quo e a evolução social como um todo, pelo menos em um sentido poderoso. Por outro lado, ele nega a noção republicana da sociedade como uma totalidade autoconsciente que é profundamente imbricada em suas partes, exatamente por causa dessa afirmação da modernização ocidental baseada na teoria sistêmica como o ponto de partida epistemológico-político para o entendimento das sociedades complexas contemporâneas. Isto significa que as sociedades contemporâneas são divididas em muitos e particulares sistemas sociais, de modo que elas não têm um núcleo básico ou um centro político a partir do qual toda a dinâmica social poderia ser regulada e dinamizada. Isso significa também que a práxis política e as instituições políticas não são mais o centro das sociedades contemporâneas, da mesma forma como elas não podem substituir a lógica, a dinâmica e os procedimentos institucionais sistêmicos por princípios político-normativos. O sistema político é uma instituição particular convivendo lado a lado com outras instituições sistêmicas, apenas isso. Além disso, Habermas não aceita a ideia republicana das classes sociais enquanto super sujeitos sociais, sendo que, aqui, ele dá razão ao liberalismo: sociedades complexas contemporâneas não possuem mais identidade e/ou divisão de classe (como o marxismo pressupõe), mas apenas indivíduos e comunidades socioculturais muito particularizados. Assim, a normatividade social não pode ser centralizada e monopolizada por uma classe social específica - de fato, classes sociais enquanto super sujeitos sociais já não existem mais.

Desse modo, uma política radical para uma sociedade complexa inicia a partir de dois pontos epistemológico-políticos: (a) o fato da modernização ocidental enquanto auto-diferenciação, autorreferencialidade e auto-subsistência sistêmica, que se constitui em um processo consolidado; (b) a centralização e a monopolização da normatividade social e da práxis política nas e pelas instituições jurídico-políticas (cf. HABERMAS, 2003b, p. 72, p. 105, p. 147-148). No primeiro caso, temos duas consequências: a política deve respeitar a autonomização e a autorreferencialidade sistêmicas, de modo que ela não pode realizar uma intervenção direta no mercado capitalista, senão que apenas uma intervenção indireta (este conceito não é tão claro na teoria de Habermas), bem como ela não pode substituir mecanismos institucionais sistêmicos que são técnicos e lógicos por princípios político-normativos (cf. HABERMAS, 2003, p. 147-148); e mesmo as instituições políticas são instituições sistêmicas, pelo menos em um sentido poderoso, isto é, elas são uma arena formal com procedimentos, regras, práticas e atores formais, o que as diferencia em relação às esferas, práticas e sujeitos sociais informais da sociedade civil (cf. HABERMAS, 2003b, p. 105-106). Como consequência, as instituições políticas não são apenas autônomas e autorreferenciais no que se refere à arena, às práticas e aos sujeitos sociais da sociedade civil, mas também diferentes, politicamente falando, significando isso que essas instituições políticas são realizadas e dinamizadas basicamente por meio de uma política representativa, centralizada nos partidos políticos e baseada naquela dinâmica institucional sistêmica que é própria da modernização ocidental. No segundo caso, a inexistência de classes sociais enquanto macro sujeitos leva à centralização e à monopolização institucional da normatividade social por parte das próprias instituições políticas com seu procedimentalismo interno e com seu pessoal autorizado 
(tais como partidos políticos e cortes). Aqui, nenhuma classe social ou sujeito político individual pode centralizar e monopolizar a normatividade social em nome de toda a sociedade, muito menos realizar uma práxis social emancipatória baseada em tal noção de normatividade social - instituições jurídico-políticas assumem a guarda, o fomento e a fundamentação da normatividade social para toda a sociedade, a partir de uma política representativa que enfatiza o institucionalismo como a condição basilar para a legitimação e a evolução sociais ao longo do tempo (cf. HABERMAS, 2003b, p. 24).

Como eu penso, a teoria da modernidade de Habermas e seu consequente paradigma jurídico-político procedimentalista leva ao institucionalismo forte no que diz respeito à legitimação e à condução da evolução social. Com o conceito de institucionalismo forte eu quero significar o fato de que as instituições sistêmicas têm uma lógica de funcionamento e de programação muito própria e fechada que é basicamente autônoma, autorreferencial e auto-subsistente em relação a uma práxis política democrática inclusiva e a um modelo de normatividade social que possa enquadrar a organização institucional sistêmica desde fora e com base em princípios político-normativos. Uma instituição sistêmica é fundamentalmente técnica e lógica, e ela tem uma independência completa no que diz respeito às instituições políticas e à práxis espontânea (e politizada!) dos movimentos sociais e das iniciativas cidadãs. Portanto, cada sistema social tem um poder como que absoluto sobre sua própria constituição, legitimação e evolução ao longo do tempo, tornando-se fechado aos contextos, princípios, práticas e atores exteriores. $\mathrm{O}$ institucionalismo forte significa que as instituições sistêmicas centralizam e monopolizam seus campos sociais específicos, particularizando-os e tornando-os despolitizados. A teoria da modernidade de Habermas, no momento em que assume a noção liberal de modernização ocidental enquanto auto-diferenciação, autorreferencialidade e auto-subsistência sistêmica, tem de aceitar uma consequência política muito prejudicial, a saber, o fechamento e a autonomia sistêmicos em relação à práxis política, exatamente pelo fato de que as instituições sistêmicas são estruturas não-normativas e despolitizadas, caracterizadas por uma dinâmica de funcionamento e de programação lógica e técnica. Além disso, quando Habermas assume que as sociedades complexas contemporâneas não possuem um núcleo e um centro político, da mesma forma como não possuem classes sociais enquanto sujeitos políticos macro, ele deve aceitar o fato de que as instituições jurídico-políticas centralizam e monopolizam a fundamentação e o fomento da normatividade social, o que implica na consolidação da política representativa como a base epistemológico-política para a legitimação e para a evolução de uma sociedade democrática. Aqui, os movimentos sociais da sociedade civil e as iniciativas cidadãs têm um status secundário e periférico - o mais importante é o próprio institucionalismo.

\section{MARX SOBRE A MODERNIZAÇÃO OCIDENTAL: UMA PROPOSTA E ALGUMAS CONCLUSÕES}

O problema da nova esquerda é exatamente a afirmação da noção conservadora de modernização ocidental enquanto auto-diferenciação, autorreferencialidade e auto-subsistência institucional sistêmica, que é uma pressuposição epistemológico-política liberal. Ela submete a práxis política e as instituições políticas à lógica e à dinâmica sistêmicas, limitando a capacidade política de enquadrar os sistemas sociais em geral e o mercado capitalista em particular. E a teoria institucional sistêmica leva ao institucionalismo forte, no sentido de que cada sistema social centraliza e monopoliza a constituição, a legitimação e a evolução de seu campo correlato, fechando-o e tornando-o autônomo em relação à práxis política e à normatividade social. Do mesmo modo, o institucionalismo forte na política (que é a consequência dessa concepção conservadora de modernização ocidental) significa que as instituições políticas centralizam e monopolizam a dinamização da normatividade social, além de se tornarem a arena política, os procedimentos, as normas e os atores efetivos a partir dos quais a evolução social é legitimada e realizada, estabelecendo a política representativa (que está limitada pelos sistemas sociais despolitizados e não-normativos) enquanto a base 
para a constituição e para a evolução social ao longo do tempo. Assim, a intenção de Habermas de formular um paradigma político radical para as sociedades complexas contemporâneas revela-se pouco radical e, em verdade, muito conservadora, porque está presa à noção liberal conservadora de sistema social como uma estrutura autônoma, autorreferencial e auto-subsistente, que é não-política e não-normativa, apenas técnica e lógica.

Aqui, nós podemos fazer uso de uma intuição de Karl Marx enquanto contraponto epistemológico-político à teoria sistêmica do liberalismo conservador e da nova esquerda para o entendimento da modernização ocidental: há uma estrita interdependência entre reprodução social e dinâmica econômica, no sentido de que o campo econômico está dentro da esfera social constituída pela práxis política, que é uma atividade humana social e produtiva, dinamizada por classes sociais em conflito (cf. MARX, 2013; MARX \& ENGELS, 2008). A partir disso, não há uma auto-diferenciação, autorreferencialidade e auto-subsistência institucional sistêmica, e também não há consequentemente a separação entre dinâmica institucional sistêmica $e$ mundo da vida. Tal interdependência profunda entre evolução social, constituição econômica e práxis política leva ao fato de que a dinâmica social e a estruturação institucional são o resultado de uma ação política que objetiva dinamizar e criar não apenas códigos e práticas institucionais relacionados a uma esfera social singular enquanto separada da sociedade como um todo, senão que ela também objetiva (e essa é a mais impressionante contradição liberal) estruturar as instituições políticas e o status quo baseada naquela noção política de instituição sistêmica enquanto um campo fechado, autônomo, autorreferencial e auto-subsistente. Desse modo, a ideia de uma instituição sistêmica serve não apenas para legitimar a lógica e a dinâmica institucional sistêmica, mas também para determinar a constituição política e a evolução social como uma totalidade imbricada e dependente. Esse é o sentido da política negativa e do laissez-faire propugnados pelo liberalismo conservador: orientar a constituição política institucional e a evolução social como um todo enquanto dependentes da lógica e da dinâmica de mercado, e não apenas orientar o próprio entendimento e a própria autoconstituição do mercado.

A noção de interdependência entre infraestrutura e superestrutura de Marx - que é baseada (a) na compreensão de sociedade como uma totalidade imbricada, (b) na evolução política da sociedade e de suas instituições, e (c) na existência de macro sujeitos sociais em conflito - nos possibilita enfrentar a despolitização e a constituição não-normativa das instituições sistêmicas ao ligar dinâmica sistêmica e evolução sócio-política, o que significa que as instituições sistêmicas não são fechadas e autorreferenciais no que se refere à política e à normatividade social, da mesma forma como elas não possuem uma ação técnica e lógica que é sempre particularizada e relacionada com seu campo específico: elas têm tanto uma dimensão e uma constituição políticas, quanto um impacto sócio-político macro. Desse modo, instituições sistêmicas tornam-se estruturas abrangentes que dinamizam e que determinam toda a evolução social (não apenas um campo social particular e autorreferencial), ao mesmo tempo em que se tornam estruturas políticas que dependem da hegemonia de classe. Em outras palavras, instituições sistêmicas - e em especial o mercado capitalista - são basicamente instituições políticas estruturais. Esta é a importante contribuição teórico-política do marxismo: ela nos possibilita entender a constituição e a ação institucional sistêmica como uma práxis política que tem consequências estruturais e amplas, que também envolvem sujeitos sociais macro. $O$ mercado não é um campo particularizado e fechado, mas uma totalidade que integra $\mathrm{e}$ que determina todos os campos e sujeitos sociais a partir de sua dinâmica, definindo-os, da mesma forma como ele define a constituição, a legitimação e a evolução política institucional. E o mercado capitalista enquanto uma macro estrutura política é dinamizado por sujeitos sociais também com estruturação macro, que, agindo como classe, definem a evolução social e a constituição política institucional como um todo a partir da lógica e da dinâmica econômica. 
Baseado nessa intuição marxista da constituição política da sociedade enquanto uma totalidade imbricada, argumento que nosso grande problema (tanto político quanto epistemológico), hoje, consiste em tal concepção liberal de modernização ocidental enquanto auto-diferenciação, autorreferencialidade e auto-subsistência institucional sistêmica, ou seja, a constituição e a legitimação institucional sistêmica não-política e não-normativa que leva ao institucionalismo forte e à particularização da base e dos efeitos sistêmicos. De fato, este entendimento institucional sistêmico da modernização ocidental é atualmente a grande tendência tanto no liberalismo conservador quanto na nova esquerda, sendo que ele conduz a uma conclusão muito similar em ambas as posições teórico-políticas: já não é mais possível uma intervenção política direta nas instituições sistêmicas, da mesma forma como elas não podem sofrer intervenção com base em princípios e em práticas político-normativos, pelo fato de que instituições sistêmicas têm uma dinâmica autorreferencial e auto-subsistente que as particulariza e as autonomiza em relação à práxis político-normativa direta. Nesse sentido, instituições sistêmicas, enquanto campos particularizados, possuem uma constituição, uma legitimação e uma evolução basicamente técnica e lógica, o que significa exatamente sua estruturação não-política e não-normativa - essa é a razão pela qual uma intervenção político-normativa direta nas instituições sistêmicas não é legitimada pelas teorias sistêmicas (e mesmo por Habermas). Contudo, como mostrei acima, esta é uma noção falsa: a constituição, a evolução e as consequências institucionais sistêmicas apresentam um alcance macro que subsume e que dinamiza toda a evolução social e toda a estruturação e a evolução políticas. Portanto, a lógica e a dinâmica institucional sistêmica não é neutra, imparcial ou autônoma e fechada em relação tanto aos sujeitos sociais quanto ao seu enraizamento e aos seus efeitos sociais - a lógica e a dinâmica institucional sistêmica estão fundadas no social e representam instituições macro que interligam e que determinam a evolução de todas as esferas sociais, também unindo fortemente todos os sujeitos sociais em um projeto político e em uma evolução social comuns.

É interessante, aqui, mencionar Thomas Piketty e Adriano Benayon como exemplo de intelectuais que interpretam a teoria econômica relacionada à modernização ocidental contemporânea (e mesmo no que diz respeito à economia de um todo) basicamente, fundamentalmente como um campo político, como uma teoria política ${ }^{2}$. De fato, ambos os intelectuais apresentam duas ideias imbricadas como ponto de partida epistemológico-político para o entendimento do processo contemporâneo de modernização econômica: (a) não existe laissez-faire, no sentido de uma autorreferencialidade e auto-subsistência econômica; e (b) tudo é política e político (cf. PIKETTY, 2014; BENAYON, 1998). Tais ideias significam o fato de que a constituição, a legitimação e a evolução econômica não são separadas da sociedade enquanto uma totalidade, bem como das instituições políticas e da práxis política como um núcleo societal, em um duplo sentido: a economia é uma estrutura macro que determina o status quo e a constituição política institucional; a economia está enraizada no mundo social e define-o desde sua (da economia) lógica e dinâmica internas. Este é o sentido da economia enquanto um campo político-normativo e como uma práxis político-normativa: ela estabelece a configuração de todos os campos sociais e das instituições políticas, no mesmo sentido em que sua estruturação e sua evolução dependem das lutas sociais entre sujeitos sociais macro. Como estrutura sistêmica totalizante que é resultado de e definida por lutas sociais entre sujeitos políticos macro, a economia torna-se totalmente politizada e normativa. Aqui, uma intervenção político-normativa direta é legitimada e necessária para a estabilização econômica e para a evolução social - a estruturação e a legitimação lógica e técnica da economia são pura fantasia conservadora.

Ora, penso que a questão teórico-política central das sociedades contemporâneas é a disputa acerca da compreensão hegemônica da modernização ocidental. Em outros termos, nossa dinâmica teórico-política fundamental está baseada nas e determinada pelas lutas sócio-políticas em torno à compreensão da modernização econômico-política, suas especificidades, seu campo e seus princípios, sua crise - e a posição 
teórico-política hegemônica acerca dela definirá o caminho, os instrumentos e mesmo os atores políticos que assumirão o papel de base normativo-política para o enquadramento e para a evolução dessa mesma modernização econômico-política. Desse modo, a definição do sentido da modernização ocidental é sempre o principal fundamento político para a política contemporânea, bem como para dinamizar nossa evolução como sociedade ou como globalização. Esta é a razão pela qual uma democracia radical, uma teoria social crítica radical e uma esquerda radical devem superar o entendimento da modernização ocidental fundada na auto-diferenciação, na autorreferencialidade e na auto-subsistência institucional sistêmica, afirmando uma concepção teórico-política alternativa, baseada no conceito de sociedade como uma totalidade imbricada em suas partes, o que significa a ideia de que há uma profunda ligação entre infraestrutura e superestrutura, que leva à politização e à constituição normativa dos sistemas ou das instituições sociais.

O liberalismo conservador está muito forte hoje, sendo que, atualmente, ele é a plataforma teórico-política hegemônica para o entendimento e para a resolução da atual crise sócio-econômica, tanto em nível nacional quanto em nível internacional. Ele enfatiza as especificidades, a autonomia e a autorreferencialidade do mercado, ou seja, a constituição e a legitimação lógica e técnica desse mesmo mercado, como a base e o ponto de partida seja para a compreensão da constituição e da evolução da modernização ocidental, seja para a resolução da atual crise sócio-econômica. Assim, desde uma perspectiva conservadora, a práxis política e as instituições políticas tornam-se um problema, pelo fato de que elas intencionam politizar e regular a dinâmica econômica por meio de uma noção vinculante de normatividade social. Ora, em tal caso, o mote central do conservadorismo consiste exatamente em despolitizar o campo econômico, transformando-o em um mundo técnico e lógico, e reduzindo as discussões político-normativas sobre economia a argumentos técnicos e lógicos: aqui, a economia torna-se uma ciência e uma técnica pura, exata e fortemente objetiva, monopolizada por instituições econômicas sistêmicas. Esse cientificismo econômico despolitiza a constituição e a legitimação econômicas, da mesma forma como retira da economia sua estruturação e sua dependência normativas. Desde uma posição institucional sistêmica conservadora, a economia não pode ser enquadrada por argumentos político-normativos.

Uma práxis política critica de esquerda, que é muito urgente, deve recusar o cientificismo econômico ideológico do conservadorismo; também deve rejeitar a redução liberal da economia a um campo, a princípios e a atores técnicos e lógicos. Como Piketty e Benayon disseram, tudo é política e político, incluindo o laissez-faire liberal, isto é, a noção de modernização ocidental como auto-diferenciação, autorreferencialidade e auto-subsistência sistêmica. A despolitização conservadora das instituições sistêmicas é uma questão política, da mesma forma como ela possui intenções e consequências políticas, principalmente o institucionalismo forte no que diz respeito tanto à dinâmica econômica quanto às instituições políticas. Desse modo, a politização da modernização ocidental, por parte da esquerda, poderia estimular uma práxis política democrática que teria condições de clarificar a constituição e a legitimação econômica como um campo e uma prática político-normativos, com vistas a oferecer um contraponto teórico-político ao conservadorismo. Esta é a tarefa teórico-política mais importante e urgente tanto para uma teoria social crítica quanto para a esquerda: democratizar a economia política, ou seja, torná-la um assunto democraticamente acessível; torná-la uma questão político-normativa, mostrando sua dependência, sua estruturação e sua legitimação político-normativa. A teoria social crítica e a esquerda não podem assumir acriticamente uma compreensão sistêmica de modernização ocidental como seu ponto de partida teórico-político, da mesma forma como elas não podem fundar sua práxis política e suas diagnoses teóricas na constituição e na legitimação técnica e lógica da economia. A teoria institucional sistêmica, baseada na constituição técnica e lógica das instituições sistêmicas, leva à despolitização dos sistemas sociais e ao institucionalismo forte no que se refere à constituição e à legitimação sistêmicas ao longo do tempo. A teoria social crítica e a esquerda devem enfrentar tal situação desde uma mudança paradigmática que 
possa politizar a estruturação e a legitimação institucional sistêmica - a recusa, por parte da esquerda, em conceber a economia em particular e as instituições sistêmicas em geral enquanto estruturas técnicas e lógicas é o ponto de partida basilar para isso.

Além disso, a teoria social crítica e a esquerda devem organizar e empoderar as forças da sociedade civil, tais como movimentos sociais e iniciativas cidadãs. Movimentos sociais e iniciativas cidadãs são sujeitos políticos fundamentais para se quebrar a lógica sistêmica na política, bem como para deslegitimar essa noção conservadora de modernização ocidental como auto-diferenciação, autorreferencialidade e auto-subsistência institucional sistêmica, instituindo um modelo político-normativo alternativo de vida social. Em outras palavras, somente movimentos sociais e iniciativas cidadãs podem politizar a compreensão de modernização ocidental através da luta permanente contra o institucionalismo sistêmico conservador. Eles possuem uma organização vital espontânea que não é técnica ou lógica, bem como suas necessidades vitais são basicamente necessidades normativas. A partir disso, os movimentos sociais e as iniciativas cidadãs valoram a vida social com base em uma noção geral de sociedade e em um sentido da vida significativo, que não podem ser reduzidos ao entendimento técnico e lógico das instituições sistêmicas. Como consequência, os movimentos sociais e as iniciativas cidadãs politizam a constituição e a legitimação institucional sistêmica, submetendo tais instituições sistêmicas a fundamentos normativos. Aqui, apenas uma práxis política democrática inclusiva pode oferecer a legitimação às instituições sistêmicas, ao substituir uma discussão e uma práxis lógicas e técnicas por uma práxis e por uma discussão político-normativas. Ora, se a teoria social crítica e a esquerda querem oferecer uma contraposição teórico-política ao conservadorismo no que se refere à concepção de modernização ocidental, então elas devem andar lado a lado com os movimentos sociais e com as iniciativas cidadãs, formulando e tornando hegemônica uma noção político-normativa de modernização ocidental que enfatiza a politização dos sistemas sociais, assim como seu enraizamento e ligação sociais.

Acima de tudo, não existe um processo ou uma noção estilizada de modernização ocidental enquanto um processo evolutivo essencial ou naturalizado, como o liberalismo conservador objetiva afirmar, com sua noção de modernização ocidental enquanto auto-diferenciação, autorreferencialidade e auto-subsistência sistêmica. Portanto, não há uma estruturação, uma legitimação e uma dinâmica sistêmicas de cunho técnico e lógico; tudo é política e político, incluindo a economia. Com isso, a teoria social crítica e a esquerda devem entender a modernização ocidental em geral e a economia capitalista em particular como um campo e um assunto políticos, não como um campo e uma questão técnicos e lógicos, conforme pressuposto pela teoria sistêmica (assumida pela nova esquerda). A teoria social crítica e a esquerda política não podem fundar sua práxis política em tal concepção sistêmica de modernização ocidental, mesmo se elas buscam uma conciliação entre teoria sistêmica e uma práxis político-normativa - como a nova esquerda faz. Com efeito, o grande equívoco da nova esquerda consiste em assumir a noção de institucionalismo sistêmico do liberalismo conservador como base teórico-política para o entendimento e para o enquadramento da modernização ocidental contemporânea. Como mostrei acima, a teoria sistêmica e uma práxis político-normativa não podem ser conciliadas, pelo fato de que a teoria sistêmica está baseada na despolitização e na tecnicização das instituições, o que leva ao fechamento sistêmico e ao institucionalismo forte, tanto em termos de economia política, quanto em termos de práxis política democrática. Desse modo, uma práxis política radical para uma teoria social crítica e para uma esquerda política recusa a teoria sistêmica conservadora em relação ao entendimento da modernização ocidental, assumindo uma noção político-normativa de modernização que está baseada na ideia de sociedade como uma totalidade imbricada em suas partes e dependente da reprodução social político-normativa, o que significa, neste caso, tanto a intersecção entre infraestrutura e superestrutura quanto a centralidade normativo-política dos movimentos sociais e das iniciativas cidadãs advenientes da sociedade civil. 


\section{NOTAS}

1. Estou usando, neste texto, o conceito de nova esquerda de modo a significar a geração de pensadores relacionados à social-democracia europeia, caracterizada pela recusa do socialismo e particularmente do marxismo enquanto chave epistemológico-política para o entendimento e a transformação da modernização ocidental contemporânea (cf.: Habermas, 1991; Giddens, 1996). De todo modo, eu peço a gentileza aos leitores para com este conceito genérico que eu não explicarei de modo mais específico ao longo do artigo.

2. Também Paul Krugman, que é um economista liberal, acredita que a primeira condição para o entendimento da economia é o fato de que ela é uma economia política, não um campo ou uma práxis técnica e lógica (cf.: KRUGMAN, 2009). É claro, Habermas e Giddens, como exemplo da nova esquerda, também interpretam a modernização econômica ocidental a partir de um ponto de partida político. Contudo, como desenvolvi neste artigo, sua base epistemológico-política, isto é, a auto-diferenciação, a autorreferencialidade e a auto-subsistência institucional sistêmica, leva fortemente à despolitização e à autonomização institucional sistêmica no que diz respeito a uma práxis política democrática radical e inclusiva, da mesma forma como ela conduz à política representativa enquanto a plataforma política para a evolução democrática contemporânea (cf. HABERMAS, 1990, 1999; GIDDENS, 2000, 2001).

\section{REFERÊNCIAS BIBLIOGRÁFICAS}

ABENDROTH, Wolfgang. 1977. A história social do movimento trabalhista europeu. Tradução de Ina de Mendonça. Rio de Janeiro: Paz e Terra.

BENAYON, Adriano. 1998. Globalização versus desenvolvimento. Brasília: LGE.

BERNSTEIN, Eduard. 1982. Las premisas del socialismo y las tareas de la socialdemocracia. Traducción de Irene del Carril y de Alfonso García Ruiz. Madrid: Signo Veintiuno Editores.

BOBBIO, Norberto. 1986. O futuro da democracia: uma defesa das regras do jogo. Tradução de Marco Aurélio Nogueira. Rio de Janeiro: Paz e Terra.

BUTLER, Eamon. 1987. A contribuição de Hayek às ideias politicas e econômicas de nosso tempo. Tradução de Carlos dos Santos Abreu. Rio de Janeiro: Instituto Liberal.

ESPING-ANDERSEN, Gosta. 2008. Trois leçons sur l'État-providence. Traduit de l'anglais par Marianne Groulez. Paris: Éditions du Seuil..

GIDDENS, Anthony. 1996. Para além da esquerda e da direita: o futuro da política radical. Tradução de Alvaro Hattnher. São Paulo: Editora da UNESP.

2000. A terceira via: reflexões sobre o impasse da social-democracia. Tradução de Maria Luiza X. de A. Borges. Rio de Janeiro: Record.

2001. A terceira via e seus críticos. Tradução de Ryta Vinagre. Rio de Janeiro: Record,.

HABERMAS, Jürgen. Teoria da ação comunicativa (Vol. I): racionalidade da ação e racionalização social. Tradução de Paulo Astor Soethe. São Paulo: Martins Fontes, 2012a.

2012b. Teoria da ação comunicativa (Vol. II): sobre a crítica da razão funcionalista. Tradução de Flávio Beno Siebeneichler. São Paulo: Martins Fontes. 
2003a . Direito e democracia: entre facticidade e validade (Vol. I). Tradução de Flávio Beno Siebeneichler. Rio de Janeiro: Tempo Brasileiro.

2003b. Direito e democracia: entre facticidade e validade (Vol. II). Tradução de Flávio Beno Siebeneichler. Rio de Janeiro: Tempo Brasileiro.

1997. Ensayos políticos. Traducción de Ramón Garcia Cotarelo. Barcelona:

Ediciones Península.

1999. Problemas de legitimación en el capitalismo tardio. Traducción de José Luis Etcheverry. Madrid: Ediciones Cátedra.

1990. Para a reconstrução do materialismo histórico. Tradução de Carlos Nelson Coutinho. São Paulo: Brasiliense.

1991. La necesidad de revisión de la izquierda. Traducción de Manuel Jiménez Redondo. Madrid: Editorial Tecnos.

2000. La Constelación posnacional: ensayos políticos. Traducción de Pere Fabra Abat, Daniel Gamper Sachse y Luis Pérez Díaz. Barcelona: Ediciones Paidós.

2009. Europe: the faltering project. Translated by Ciaran Cronin. Cambridge:

Polity Press.

1998. "Paradigms of law", p. 13-25. In: ROSENFELD, Michael; ARATO, Andrew (Eds.). Habermas on law and democracy: critical exchanges. Los Angeles: University of California Press.

HARRINGTON, Michael. 1999. “Socialismo: passado e futuro”, p. 87-144. In: HOOK, Sidney; et al. A social-democracia nos Estados Unidos. Tradução de Rodrigo Sardenberg. Brasília: Instituto Teotônio Vilela.

HARTMANN, Martin; HONNETH, Axel. 2009. "Paradojas del capitalismo”, p. 389-422. In: HONNETH, Axel. Crítica del agravio moral: patologías de la sociedad contemporánea. Traducción de Peter Storandt Diller. Buenos Aires: Fondo de Cultura Económica.

HARVEY, David. 2008. O Neoliberalismo: História e Implicações. Tradução de Adail Sobral e de Maria Stela Gonçalves. São Paulo: Edições Loyola.

HAYEK, Friedrich August von. Individualism and economic order. London: Routledge, 1948.

2013. Law, legislation and liberty (3 vols.). London: Routledge. . 1987. O caminho de servidão. Tradução de Ana Maria Capovilla et al. Rio de Janeiro:

Instituto Liberal.

1995. Arrogância fatal: os erros do socialismo. Tradução de Ana Maria Capovilla e de Candido Mendes Prunes. Porto Alegre: Ortiz Editores.

HERRNSTEIN, Richard. 1975. O Q.I. na meritocracia. Tradução de Edmond Jorge. Rio de Janeiro: Zahar Editores. 
HOOK, Sidney. 1999. “O sentido moral da social-democracia”, p. 13-38. In: HOOK, Sidney; et al. A social-democracia nos Estados Unidos. Tradução de Rodrigo Sardenberg. Brasília: Instituto Teotônio Vilela.

KOLAKOWSKI, Leszek. 1999. "O desafio social-democrata”, p. 39-49. In: HOOK, Sidney; et al. A socialdemocracia nos Estados Unidos. Tradução de Rodrigo Sardenberg. Brasília: Instituto Teotônio Vilela.

KRUGMAN, Paul. 2009. O Regresso da economia da depressão e a crise actual. Tradução de Alice Rocha, de Saul Barata e de Alberto Gomes. Lisboa: Editorial Presença.

MARX, Karl. 2013. Manuscritos econômico-filosóficos. Tradução de Alex Marins. São Paulo: Martins Claret.

MARX, Karl; ENGELS, Friedrich. 2008. A ideologia alemã. Tradução de Luis Claudio de Castro e Costa. São Paulo: Martins Fontes.

OFFE, Claus. 1984. Problemas estruturais do Estado capitalista. Tradução de Bárbara Freitag. Rio de Janeiro: Tempo Brasileiro.

1994. Capitalismo desorganizado: transformações contemporâneas do trabalho e da política. Tradução de Wanda Caldeira Brant. São Paulo: Brasiliense.

PIKETTY, Thomas. 2014. O capital no século XXI. Tradução de Monica Baumgarten de Bolle. Rio de Janeiro: Intrínseca.

ROSANVALLON, Pierre. 1998. A Nova Questão Social: Repensando o Estado Providência. Tradução de Sérgio Bath. Brasília: Instituto Teotônio Vilela. 